\title{
Uncommon Variant of Wellens' Syndrome: A Case Report and Review of Literature
}

\author{
Layal Mansour, MD; Elie Chammas, MD, FESC, FACC ${ }^{1,2}$; Fida Charif, MD³; Mohamad Jihad Mansour, MD ${ }^{1,2 *}$ \\ 1. Lebanese University, Faculty of Medical Sciences, Hadath, Lebanon \\ 2. Division of Cardiovascular Medicine, Clemenceau Medical Center, Beirut, Lebanon \\ 3. Division of Pulmonary Medicine, Beirut Cardiac Institute, Beirut, Lebanon
}

Abstract: A 48-year-old male was admitted to the emergency department because of intermittent chest pain of 2 days duration. At the time of examination, he was pain-free. An electrocardiogram (ECG) showed biphasic $\mathrm{T}$ waves in leads V2 to V6. Troponin-I level was negative. During his transfer to the cardiac catheterization laboratory, he had a short episode of chest pain. His ECG was normal. Despite the unusual extension of biphasic T waves to the lateral precordial leads, the condition was recognized as Wellens' syndrome, which typically associates biphasic or deep symmetric T wave inversion in leads V2 and V3 during pain-free periods with a critical stenosis in the proximal left anterior descending artery. The syndrome is uncommon to medical practice but should be recognized immediately in the emergency department because it represents a pre-infarction stage and carries a high risk of mortality.

Keywords: Wellens' syndrome; coronary artery disease; acute coronary syndrome; myocardial infarction

\section{Introduction}

Wellens' syndrome (WS) is a rare condition characterized by a history of chest pain, deep symmetric T wave inversion or biphasic T waves in leads V2 and V3, absence of precordial Q waves and ST-segment elevation or depression, normal $\mathrm{R}$ wave progression, and normal or mildly elevated cardiac enzymes ${ }^{[1,2]}$ In addition, electrocardiographic (ECG) changes appear during a pain-free period and the culprit lesion is seen in the proximal left anterior descending artery $(\mathrm{LAD})^{[1,2]}$. Of patients admitted with unstable angina, this ECG pattern is seen in $14-18 \%{ }^{[1,2]}$. It is a serious syndrome because it represents a pre-infarction stage ${ }^{[3]}$. We herein report the case of a 48 -year-old man with a rare ECG pattern of WS not limited to V2 and V3, but also involving the lateral precordial leads, who was found to have a critical proximal LAD lesion that was successfully stented.

\section{Case presentation}

A 48-year-old man, heavy smoker of 30-pack-year and occasional alcohol consumer, with a non-significant past medical history but with a family history of coronary artery disease (his father died of acute myocardial infarction (MI) at the age of 60 years), presented to the emergency department for a 2-day-history of intermittent chest pain. He described the pain as sharp, oppressive in nature and retrosternal. There were no reported associated symptoms. He mentioned that three episodes occurred during exertion, each one lasting for about 10-15 minutes and relieved by rest, while another episode awoke him from sleep and pushed him to seek medical advice.

Copyright (C) 2017 Layal Mansour, MD et al.

*Corresponding author. E-mail: mohamad_J_mansour@hotmail.com. doi: $10.18686 /$ aem.v6i2.110

This is an open-access article distributed under the terms of the Creative Commons Attribution Unported License

(http://creativecommons.org/licenses/by-nc/4.0/), which permits unrestricted use, distribution, and reproduction in any medium, provided the original work is properly cited. 
On physical examination, the patient was not in distress and was pain-free. His vital signs were within normal limits. Cardiovascular examination revealed a normal S1 and S2 without murmur. Lungs were clear to auscultation. An electrocardiogram was obtained when he was pain-free and showed normal sinus rhythm with a heart rate of 75 beats per minute, mild left axis deviation, but biphasic $\mathrm{T}$ waves extending from V2 to V6 (Figure 1). Those findings suggested WS.

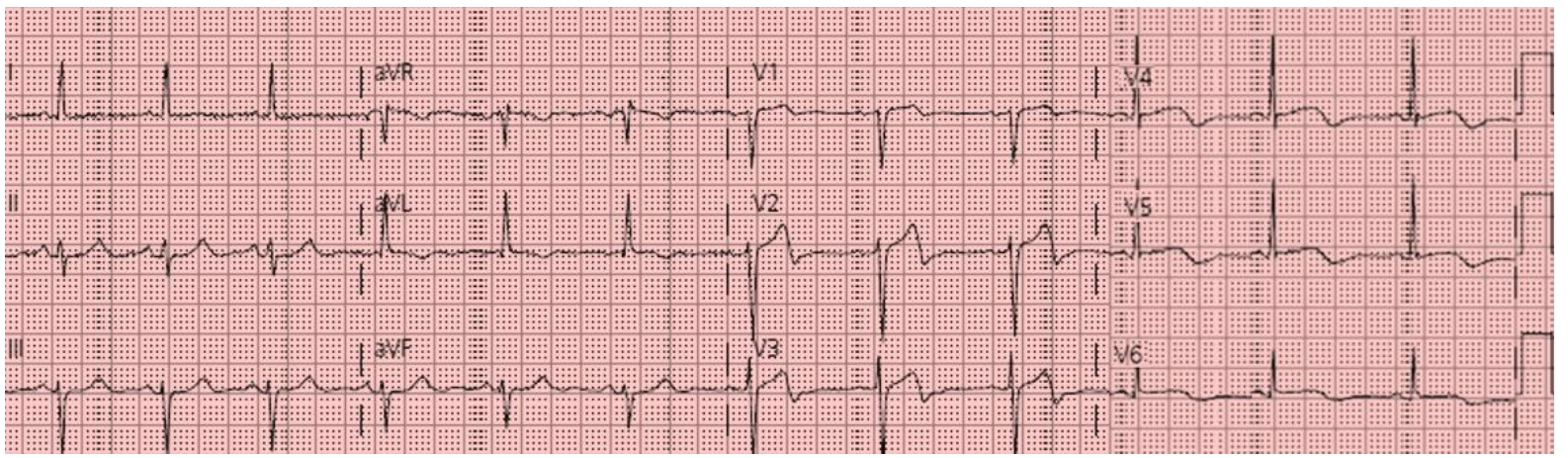

Figure 1. ECG changes before coronary angioplasty during a pain-free period, showing diffuse biphasic T waves from V2 to V6.

He received loading doses of acute coronary syndrome treatment and was prepared for coronary angiography. A complete metabolic panel including complete blood cell count with differential, renal function, liver function tests and electrolytes were within normal ranges. Troponin-I level was $0.06 \mathrm{ng} / \mathrm{mL}$ (cut-off value 0.08 ). Lipid profile showed elevated LDL-C of $171 \mathrm{mg} / \mathrm{dL}$.

During his transfer to the cardiac catheterization laboratory, he experienced another episode of chest pain that was relieved by isosorbide dinitrate $5 \mathrm{mg}$ sublingually. ECG during pain was normal and did not show ST-segment elevation or depression, nor T wave changes. An urgent coronary angiogram confirmed the diagnosis of WS with $90 \%$ occlusion in the proximal LAD (Figure 2A). There were no significant stenoses in the remaining coronary arteries. Angioplasty with a drug eluting stent was performed successfully on the culprit lesion (Figure 2B). A transthoracic echocardiogram was completely normal.

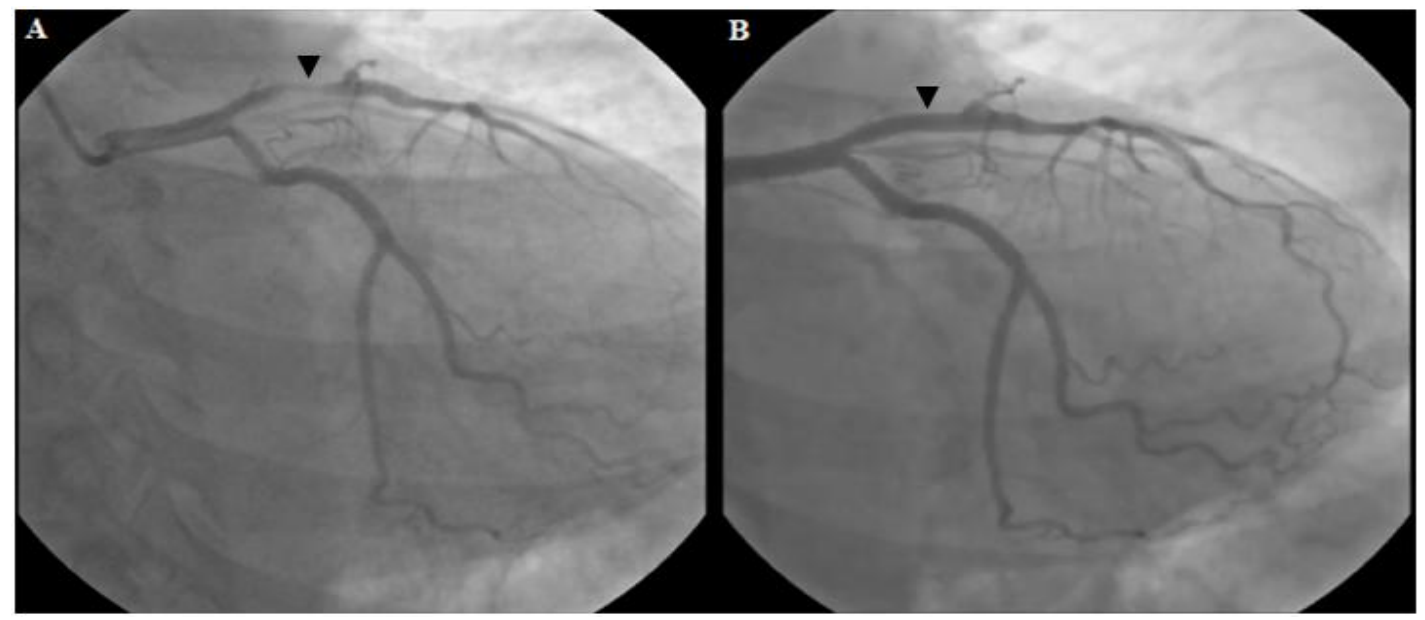

Figure 2. (A) Coronary angiogram revealing $90 \%$ occlusion of the proximal LAD (arrowhead). (B) Coronary angiogram showing complete revascularization after placement of a drug eluting stent (arrowhead).

The patient was clinically and hemodynamically stable and was discharged the next day on ticagrelor $90 \mathrm{mg}$ orally twice daily, aspirin $100 \mathrm{mg}$ orally daily, bisoprolol $2.5 \mathrm{mg}$ orally daily, ramipril $5 \mathrm{mg}$ orally daily and atorvastatin $40 \mathrm{mg}$ orally daily. 


\section{Discussion}

WS was first described by Gerson et al in 1980 as an inverted U-wave, and again in 1982 by De Zwaan, Wellens and colleagues as $\mathrm{WS}^{[1,2,4]}$. It is an uncommon condition to the medical practice because it accounts for $10-15 \%$ of all acute coronary syndromes ${ }^{[3]}$. However, recognizing the syndrome is crucial. It is typically diagnosed in a patient with a history of chest pain presenting during a pain-free interval, with an ECG showing biphasic or deep inverted symmetric $\mathrm{T}$ waves in the anterior precordial leads ${ }^{[1,2]}$. The condition carries significant diagnostic and prognostic values because it represents a pre-infarction stage ${ }^{[3]}$.

If a classical WS is kept untreated, the critical lesion of the proximal LAD will lead to massive acute anterior wall myocardial infarction (AWMI) in nearly $75 \%$ of cases, with subsequent left ventricular impairment ${ }^{[5]}$. Moreover, there are two types of WS. Type A accounts for approximately $25 \%$ of all cases and refers to the classical biphasic T waves in leads V2 and V3, whereas type B accounts for $75 \%$ of cases and refers to symmetric deep T wave inversions in the same leads ${ }^{[3,6]}$. In both cases, cardiac enzymes are first normal or mildly elevated and ECG changes are detected during a pain-free period and exclude pathologic $\mathrm{Q}$ waves.

Based on the above mentioned criteria, the positive predictive value of WS is approximately $86 \%{ }^{[3]}$. Another study by Haines et al reported a specificity of $89 \%{ }^{[7]}$. For this reason, it is of paramount importance that the syndrome be recognized as it allows rapid and appropriate aggressive management, prevention of prolonged emergency care or inappropriate conservative therapy as these patients may be destined for a massive AWMI.

Another issue of interest is stress testing. A review by Tandy et $a^{[8]}$ advises that stress testing be cautioned in the presence of suspected left main-equivalent lesions. Of interest, of the few reviews reported, a majority of them was published in emergency medicine journals, highlighting the importance of recognition of the syndrome.

In our case, ECG performed during chest pain was normal. However, when the patient was pain-free, ECG showed atypical changes that raised the suspicion of WS, because T waves were biphasic, accounting for the rare type of the syndrome, and extended from leads V2 to V6, which are even rarer and occasionally seen. If kept unrecognized, a second set Troponin-I repeated after 6 hours, would have come out positive, indicating myocardial injury.

Moreover, one should be aware of the different causes that can mimic a WS. While it is a pain-free syndrome, ECG changes are not associated with left ventricular hypertrophy related to any type of cardiomyopathy, pulmonary embolism, pulmonary edema, cardiac sarcoidosis, hypokalemia, right bundle branch block, digitalis effect, stroke, subarachnoid hemorrhage, athlete's heart, electroconvulsive therapy, and hypertension ${ }^{[9,10]}$. In these cases, when biphasic or inverted $\mathrm{T}$ waves are seen, they are denoted to as pseudo-WS. Kukla et al ${ }^{[11]}$ and Abulaiti et al ${ }^{[12]}$ also described patients with characteristic $\mathrm{T}$ wave changes but their condition was attributed to a pseudo-WS due to coronary artery vasospasm.

\section{Conclusions}

ECG abnormalities in WS are not limited to leads V2 and V3. Biphasic T waves extending to the lateral leads are possible but rarely seen. This finding should not misdiagnose a WS in light of negative cardiac enzymes. Hence, coronary angiography should not be delayed. Stenting of the culprit lesion is crucial in order to prevent the development of large AWMI. Recognition of the disease is the responsibility of the emergency medicine physician because ECG changes are highly specific and represent a warning sign of critical proximal LAD stenosis.

\section{References}

1. de Zwaan C, Bar FW, Wellens HJ. Characteristic electrocardiographic pattern indicating a critical stenosis high in left anterior descending coronary artery in patients admitted because of impending myocardial infarction. Am Heart J. 1982;103:730-6. 
2. de Zwaan C, Bär FW, Janssen JH, Cheriex EC, Dassen WR, Brugada P, et al. Angiographic and clinical characteristics of patients with unstable angina showing an ECG pattern indicating critical narrowing of the proximal LAD coronary artery. Am Heart J. 1989;117(3):657-65.

3. Win Htut Oo S, Khalighi K, Archana Kodali, MD, Cho May, MD, Thein Tun Aung, MD, Snyder R. Omnious T-wave inversions: Wellens' syndrome revisited. J Community Hosp Intern Med Perspect. 2016;6(4):10.3402/jchimp.v6.32011.

4. Movahed MR. Wellen's Syndrome or Inverted U-waves? Clin Cardiol. 2008;31:133-4.

5. Smith S, Whitwam S. Acute Coronary Syndromes. Emerg Med Clin N Am. 2006;24:53-89.

6. Rhinehardt J, Brady WJ, Perron AD, Mattu A. Electrocardiographic manifestations of Wellens' syndrome. Am J Emerg Med. 2002;20:638-43.

7. Haines DE, Raabe DS, Gundel WD, Wackers FJ. Anatomic and prognostic significance of new T-wave inversion in unstable angina. Am J Cardiol. 1983;52(1):14-8.

8. Tandy TK, Bottomy DP, Lewis JG. Wellens Syndrome. Ann Emerg Med 1999;33:347-51.

9. Rautaharju PM, Surawicz B, Gettes LS, Bailey JJ, Childers R, Deal BJ. AHA/ACCF/HRS recommendations for the standardization and interpretation of the electrocardiogram: part IV: the ST segment, T and U waves, and the QT interval: a scientific statement from the American Heart Association Electrocardiography and Arrhythmias Committee, Council on Clinical Cardiology; the American College of Cardiology Foundation; and the Heart Rhythm Society. Endorsed by the International Society for Computerized Electrocardiology. J Am Coll Cardiol. 2009;53(11):982-91.

10. Said S, Bloo R, de Nooijer R, Slootweg A. Cardiac and non-cardiac causes of T-wave inversion in the precordial leads in adult subjects: A Dutch case series and review of the literature. World J Cardiol. 2015;7(2): 86-100.

11. Kukla P, Korpak-Wysocka R, Gragan J, Giszterowcz D, Dobrowolski W, Czamara M, et al. Pseudo-Wellens syndrome in a patient with vasospastic angina. Kardiol Pol. 2011;69:79-81.

12. Abulaiti A, Aini R, Xu H, Song Z. A special case of Wellens' syndrome. J Cardiovasc Dis Res. 2013;4(1): 51-54.. 